\title{
Pseudodiamesa nivosa (Goetghebuer, 1928) is not a synonym of Pseudodiamesa arctica (Malloch, 1919), but what about the separation of immature stages of these species?
}

Eugenyi A. Makarchenko

Institute of Biology and Soil Science of Russian Academy of Sciences, Vladivostok, Russia. E-mail: makarchenko@biosoil.ru

As I showed in my poster "Pseudodiamesa nivosa (Goetghebuer, 1928) is not synonym of Pseudodiamesa arctica (Malloch, 1919)" at the XVIIth Chironomid symposium in Nankai University (Makarchenko, 2009), both are a good and valid species and can be separated by some features of male imagines adduced below.

1. $\mathrm{LR}_{1}$ 0.52-0.54. Basal lobe of gonocoxite with narrow and triangular or roundish triangular apex. Tergite IX with projection of posterior-lateral angle. Gonostylus in apical 1/3 finger-shaped, with roundish apex ... P. arctica (Mall.) (Fig. 3).

- $\mathrm{LR}_{1}$ 0.65-0.69. Basal lobe of gonocoxite with wide and roundish apex. Tergite IX without projection of posterior-lateral angle. Apical 1/3 of gonostylus of different shape, with beak-shaped apex ... P. nivosa (Goetgh.) (Figs 1-2).
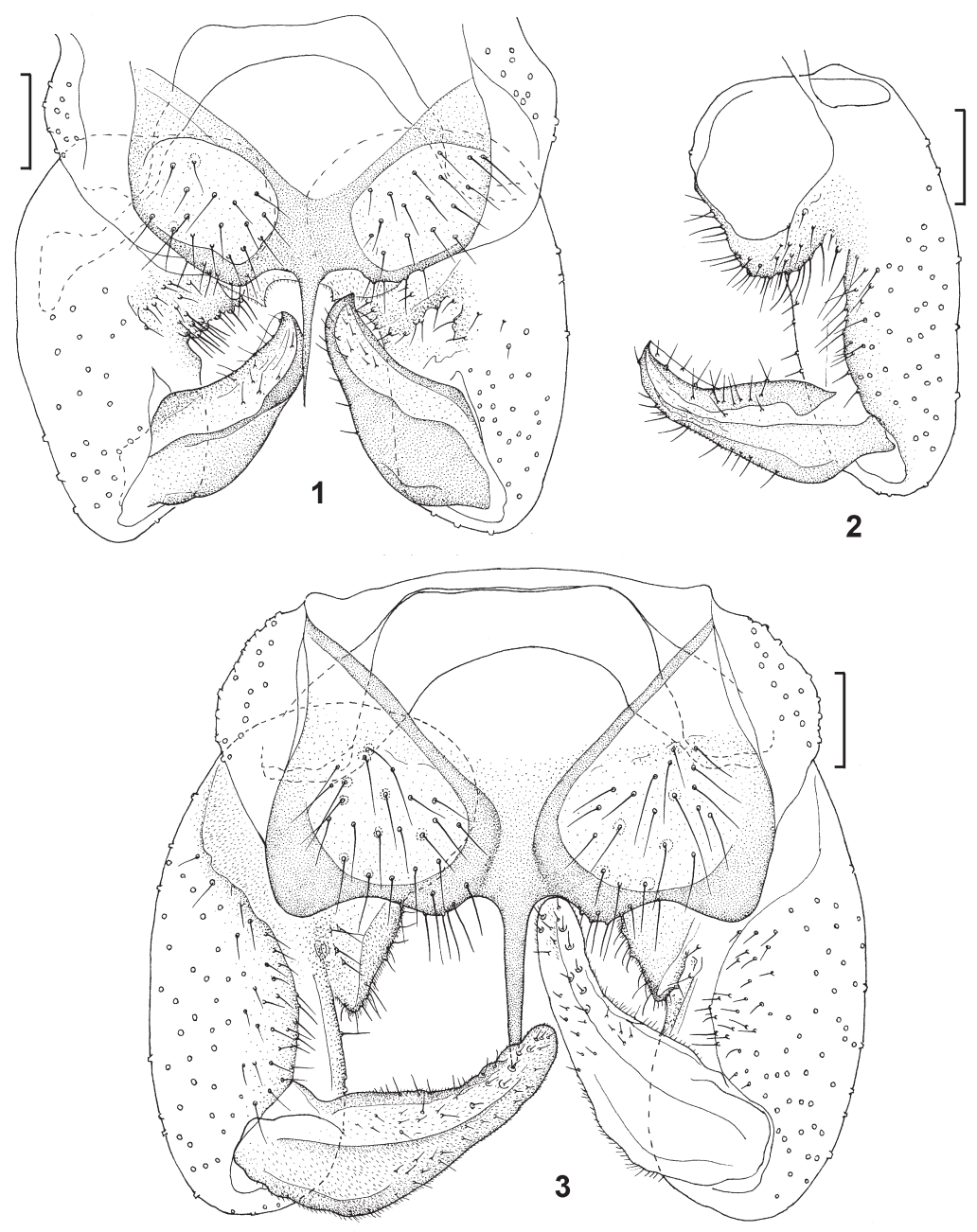

Figures 1-3. Male imagines of Pseudodiamesa nivosa (Goethebuer) from Norway (1-2) and Pseudodiamesa arctica (Malloch) from Devon Island of Canada (3). 1, 3 - total view of hypopygium, from above; 2 - gonocoxite and gonostylus. Scale bars are $100 \mu \mathrm{m}$. 
The hardest problem is to separate larvae of $P$. nivosa and $P$. arctica. Nobody has studied numerous specimens of larvae and has not checked variation of some larval features, namely shape, presence or absence of labral lamellae. When I studied larvae of the nivosa group, sometimes I checked labral lamellae, sometimes not, but in the same population of the same river. Yes, for deciding taxonomic problems of these and other species of Pseudodiamesa we need to revise the species by larvae, pupae and imago from various places of the Holarctic region using traditional morphological methods and karyology and DNA analysis. Also we need to study biology and ecology of these species because it can help us in deciding taxonomic problems. At first we need to get fresh material of $P$. nivos $a$ and $P$. arctica from type localities, which for the first is the French Alps and for the second is Arctic Canada. I think it is a good joint work for an international project and a team of chironomidologists, karyologists, molecular biologists and ecologists. I think we must and can decide this interesting problem but only all together.

\section{Let us co-operate!}

\section{References}

Makarchenko, E.A. 2009. Pseudodiamesa nivosa (Goetghebuer, 1928) is not synonym of Pseudodiamesa arctica (Malloch, 1919) (Diptera: Chironomidae). Program and abstracts XVII International Symposium on Chironomidae. July 5-10, 2009. Nankai University, Tianjin, China: 71. 